\title{
Estrutura intelectual da produção científica sobre nostalgia: uma análise bibliométrica
}

\author{
Intellectual structure of scientific production on nostalgia: a bibliometric analysis
}

\author{
Loreni Maria dos Santos Braum ${ }^{1}$ (iD), Vânia Maria Jorge Nassif ${ }^{2}$ (iD, Evandro Luiz Lopes ${ }^{3}$ (iD e André \\ Torres Urdan ${ }^{4}$ (iD
}

\begin{abstract}
${ }^{1}$ Doutorado em Administração pela Universidade Nove de Julho (Uninove), professora da Universidade Estadual do Oeste do Paraná (UNIOESTE), e-mail: lorenibraum@ hotmail.com

${ }^{2}$ Doutorado em Administração de Empresas pela Universidade Presbiteriana Mackenzie, professora da Universidade Nove de Julho (UNINOVE), e-mail: vania.nassif@gmail.com

${ }^{3}$ Doutorado em Administração pela Universidade Nove de Julho (UNINOVE), professor da UNINOVE, e-mail: elldijo@uol.com.br

${ }^{4}$ Doutorado em Administração pela Universidade de São Paulo (USP), professor da Universidade Nove de Julho (UNINOVE), email: andre.urdan@gmail.com
\end{abstract}

\section{RESUMO}

O estudo tem por objetivo identificar a estrutura da produção científica que fornece a base teórica para estudos sobre a nostalgia afim de demostrar a interlocução destas produções no processo de geração de novos conhecimentos. Quanto aos procedimentos metodológicos, trata-se de uma pesquisa exploratória com abordagem quantitativa e qualitativa, centrando-se nas técnicas bibliométricas, especificamente a análise de cocitação. Os dados para as análises são provenientes de artigos científicos, recuperados na base de dados Web of Science. Os resultados da Análise Fatorial Exploratória, cuja variância total explicada foi de 78,20\%, revelaram que as publicações que fornecem a base científica para estudos sobre a nostalgia podem ser agrupadas em cinco dimensões que foram nominadas: Efeitos positivos da nostalgia nos indivíduos; Nostalgia no comportamento do consumidor; Dimensões filosóficas e históricas da nostalgia; Nostalgia normal e patológica e, Nostalgia e significado das posses materiais. $\mathrm{Na}$ análise das cocitações, a pesquisa revelou que a quantidade de produções científicas envolvendo o tema nostalgia, nos últimos anos, vem aumentando gradativamente e nestas publicações as duas obras mais citadas foram, respectivamente, Future Nostalgia (Boym, 2001) e Yearning Yesterday (Davis, 1979). Os autores mais profícuos dentre os 289 artigos foram: Sedikides, Wildschut e Routledge. Este artigo abre perspectivas para novos estudos em outras bases científicas, além de servir de apoio para estudos empíricos, contribuindo para ampliar o conhecimento da área.

Palavras-chave: Estrutura da produção científica. Nostalgia. Cocitação. Estudos Bibliométricos.

\begin{abstract}
The study aims to identify the structure of scientific production that provides the theoretical basis for studies on nostalgia in order to demonstrate the interlocution of these productions in the process of generating new knowledge. As for the methodological procedures, this is an exploratory research with a quantitative and qualitative approach, focusing on bibliometric techniques, specifically the analysis of cocitation. Data for the analyzes come from scientific articles, retrieved from the Web of Science database. The results of the Exploratory Factor Analysis, whose total explained variance was $78.20 \%$, revealed that publications that provide the scientific basis for studies on nostalgia can be grouped into five dimensions that were named: Positive effects of nostalgia on individuals; Nostalgia in consumer behavior; Philosophical and historical dimensions of nostalgia; Normal and pathological nostalgia and, Nostalgia and meaning of material possessions. In the analysis of cocitations, the research revealed that the amount of scientific productions involving the nostalgia theme, in recent years, has been increasing gradually and in these publications the two most cited works were, respectively, Future Nostalgia (Boym, 2001) and Yearning Yesterday (Davis , 1979). The most fruitful authors among the 289 articles were: Sedikides, Wildschut and Routledge. This article opens perspectives for new studies in other scientific bases, in addition to serving as support for empirical studies, contributing to expand knowledge in the area.
\end{abstract}

Keywords: Structure of scientific production. Nostalgia. Cocitation. Bibliometric Studies. 


\section{INTRODUÇÃO}

A nostalgia é um estado emocional (Hirsch, 1992) que todas as pessoas, de todas as idades e temperamentos (fracos ou fortes) são mais ou menos suscetíveis à ela (MCCANN, 1943). Ainda que as escritas antigas não façam menção à nostalgia, desde a antiguidade as pessoas estavam familiarizadas com este sentimento (McCann, 1943). Existem diferenças nas conceituações da nostalgia, mas a maioria delas convergem para um estado afetivo, humor, ou emoção, de alguma forma desencadeado pelos pensamentos do passado (Muehling, Sprott e Sultan, 2014) que fazem parte das memórias, expressam uma busca por algo que ficou no passado, uma experiência vivida pela própria pessoa ou relatada por outra pessoa próxima à ela (DIVARD; ROBERTDEMONTROND, 1997).

No decorrer dos anos diversas definições sobre nostalgia foram surgindo e ampliando seu entendimento. A nostalgia vem sendo entendida como uma evocação (Davis, 1979), uma forma de melancolia (Turner, 1987), um estado de espírito (Belk, 1990), uma preferência por coisas que eram mais comuns no passado (Holbrook e Schindler, 1991), um estado emocional (Stern, 1992) ou uma reação afetiva (Divard e Robert-DeMontrond, 1997). A partir da tradução da dissertação de Hofer (1688) para a língua inglesa, ocorrida no ano de 1934, novos estudos sobre os efeitos da nostalgia foram surgindo e, neles, constatando que além dos efeitos negativos identificados por Hofer, efeitos positivos também podem ser associados à nostalgia, pois este sentimento é capaz de evocar boas recordações, as quais são capazes de influenciar positivamente as atititudes e intenções comportamentais.

A nostalgia pode remeter à situações agradáveis e desagradáveis, por isso é considerada por alguns pesquisadores como uma qualidade "agridoce", que é diferente da condição nostálgica individual, podendo evocar memórias pacíficas, tempos prazerosos ou de tensão e tumulto (HOLAK; HAVLENA, 1992). Quanto à idade, possivelmente em uma faixa dos dez aos setenta anos de idade é possível que as pessoas possam construir uma recuperação parcial ou seletiva de experiências passadas (HOLAK; HAVLENA, 1992). As pessoas podem ter maior ou menor grau de propensão à nostalgia, ou seja, de relembrar experiências do passado e vivenciar sentimentos por meio dessas lembranças (HOLBROOK, 1993).

O foco das pesquisas sobre nostalgia vem se expandido, uma vez que além de estudar as dimensões filosóficas e históricas, bem como patologias relacionadas à ela, há diversos estudos tratando do papel da nostalgia no significado das posses materiais, e seu uso como uma estratégia das empresas para consolidação de uma marca no mercado (Baker e Kennedy, 1994; Havlena e

Ciências Sociais Aplicadas em Revista, v. 20, n. 38, p. 291-314, semestral, janeiro-junho, 2020. 
Holak, 1991; Orth e Gal, 2014), pois ela pode ser considerada uma forma de reconexão dos consumidores com eventos passados a fim de tranquilizá-los diante das incertezas do mundo atual (Brown, Kozinets e Sherry, 2003) e, como artefato para melhorar as relações de consumo tanto com marcas nostálgicas quanto não-nostálgicas (KESSOUS; ROUX; CHANDON, 2015). Na área de marketing, por exemplo, diversos estudos sugerem que os apelos nostálgicos utilizados em embalagens podem influenciar positivamente a atitude dos consumidores, bem como suas intenções de compra (HOLBROOK, 1993; PASCAL; SPROTT; MUEHLING, 2002; MUEHLING; SPROTT, 2004; MUEHLING; PASCAL, 2012). Entre os estudos sobre nostalgia na área de marketing destacam-se os de Belk (1990); Holbrook e Schindler (1996); Divard e RobertDemonstrond (1997); Holak e Havlena (1998); Schindler e Holbrook (2003); Wildschut et al. (2006) e Kessous (2015), os quais foram relevantes por investigarem os efeitos da nostalgia, ainda não conhecidos, no comportamento dos consumidores.

Diante disso, a presente pesquisa tem por objetivo identificar a estrutura da produção científica que fornece a base teórica para estudos sobre nostalgia, buscando demostrar a interlocução destas produções no processo de geração de novos conhecimentos.

Para a obtenção dos dados das produções científicas optou-se pela base de dados Web of Science - WOS, em que foram identificadas 332 publicações sobre o tema, sendo que após o refinamento das áreas de interesse restaram 289 artigos, os quais fizeram parte das análises posteriores. Cabe destacar que neste estudo, a estrutura intelectual da produção científica que fornece o embasamento teórico para estudos sobre o uso da nostalgia é entendida como sendo a estrutura visualizada a partir do grau de similaridade de conteúdo (tema de pesquisa), a qual ao ser reunida em agrupamentos (dimensões), evidencia as relações estruturais de conectividade teóricometodológica do tema e as interconexões das pesquisas.

Referente ao ineditismo e relevância da pesquisa destaca-se o uso da análise bibliométrica que, apesar de cada vez mais recorrente na Administração nos últimos anos como forma de avaliar o conhecimento científico, ainda é escassa na temática nostalgia. E, a análise bibliométrica é capaz de fornecer "um poderoso conjunto de métodos e medidas para estudar a estrutura e o processo de comunicação científica” de uma área (BORGMAN; FURNER, 2002, p. 4).

\section{TRAJETÓRIA CONCEITUAL DA NOSTALGIA}

Os primeiros estudos sobre a nostalgia ocorreram na área de medicina sendo tratada como um problema mental, com sintomas psicológicos associados à saudade e a aspectos negativos em 
termos comportamentais. A palavra nostalgia foi usada pela primeira vez na dissertação do médico suíço Johannes Hofer no ano de 1.688, que percebeu semelhança deste sintoma com os de outra doença que já vinha sendo estudada com diferentes denominações pelo mundo. Pelos alemães foi denomida "Schweizerkrankheit", pelos franceses "Mal du pays" e pelos espanhóis, "Malatia del pais” (MCCANN, 1943). Os sintomas eram ansiedade, fadiga, palpitações, falta de apetite, tristeza geral, desesperança e, a obsessão sobre memórias de casa causando efeitos nos espíritos vitais que iam para o cérebro, privando, assim, a massa cinzenta remanescente de éteres essenciais, ou seja, comprometia o raciocínio das pessoas acometidas (MCCANN, 1943).

Hofer ao descrever a condição que levava os pacientes a uma lembrança do passado como sendo melhor que o presente, deu a esta condição o nome de nostalgie, um termo equivalente à palavra nostalgia, em inglês (McCann, 1943). A nostalgia envolvia sintomas fisiológicos e psicológicos, que remetiam ao sofrimento causado pela ânsia de voltar para casa e, foi usada para descrever o desânimo de mercenários suíços que lutavam em terras estrangeiras (Bassett, 2006).

Em relação aos sintomas negativos da nostalgia alguns autores se posicionaram ao longo do tempo. Nos séculos XX e XXI, após a tradução da dissertação de Hofer para a língua inglesa, ocorrida no ano de 1934, a nostalgia voltou a se destacar nos estudos de McCann (1943) o qual escreveu sobre os sintomas psicológicos que afetam os sistemas respiratório e circulatório, bem como outras funções corporais as quais se manifestavam nas pessoas em forma de sofrimento psicológico ocasionando perda de apetite, náuseas, apatia, desmaios e outros sintomas diversos. Alguns anos depois, Turner (1987 primeiro autor a tratar do tema nostalgia no campo do consumo) a relacionou a um sentimento de perda e declínio, uma visão melancólica do mundo contemporâneo, traduzida na ideia de uma perda de simplicidade, autenticidade e espontaneidade emocional devido a instabilidade na qual vive a civilização em uma cultura de consumo de massa e, Starobinski e Kemp (1966, p. 89) caracterizaram a nostalgia como sendo "um abalo emocional" relacionando-a com memórias dos indivíduos.

Em contraposição, outros estudos, realizados a partir da segunda metade do século XX, constataram que a nostalgia não tinha somente associação negativa, sendo que neste momento emergem pesquisas sobre as dimensões positivas. Estas pesquisas identificaram que após experimentar a nostalgia ocorre um aumento do auto-conceito dos indivíduos (Davis, 1979); também se amplia a sensibilidade de ligação com os outros (Wildschut et al., 2006) e, corroborando estes resultados Turner, Wildschut e Sedikides (2012) concluem que atitudes positivas possibilitam 
a socialização, pois depois de sentir nostalgia os indivíduos têm atitudes mais positivas com outros indivíduos que não fazem parte do seu grupo.

Ainda em termos de dimensão positiva da nostalgia, Davis (1979) argumentou que ela protege a identidade pessoal contra ameaças de descontinuidade, sendo desenvolvida pelos seres humanos como uma resposta para adaptação e estabilização diante de um problema em um mundo incerto e caótico. Kaplan (1987, p. 465) acrescenta que ela está aliada ao prazer e alegria, proporcionando "um sentimento de euforia".

A partir da constatação das dimensões positivas, há estudos sugerindo que a nostalgia, além de outros usos, pode ser uma estratégia usada pelas empresas capaz de provocar efeitos no comportamento de consumo (Stern, 1992; Pascal, Sprott e Muehling, 2002; Muehling e Pascal, 2011), pois as incertezas do presente levam as pessoas de olharem para o passado com saudade (Brown, Kozinets e Sherry, 2003) e, diante da desorientação dos consumidores, o passado de uma marca oferece segurança (CATTANEO; GUERRINI, 2012). Assim, objetos ou posses que remetem à antiguidade tornam-se instrumentais para criar este sentido desejado de passado (Belk, 1991) os quais estão associados à condição nostálgica.

\section{PROCEDIMENTOS METODOLÓGICOS}

A seleção dos artigos sobre nostalgia foi realizada na base de dados do site Web of Knowledge em janeiro de 2017 com as palavras-chave "nostalgia" e "nostalgic", no período de 1945 a 2017, sendo que esta busca resultou em 332 publicações. Em seguida procedeu-se o refinamento de onde foram escolhidas as seguintes categorias da WOS: Cultural studies (33); Business (33); History (29); Communication (27); Humanities multidisciplinary (24); Psychology social (18); Literature (18); Sociology (13); Social sciences interdisciplinary (12); Area studies (12); Psychology experimental (11); Anthropology (11); Psychology multidisciplinary (10); Film radio television (9); Ethnic studies (9); Asian studies (9); Political science (8); Music (8); Urban studies (7); Literature romance (7); History of social sciences (7); Psychology psychoanalysis (6); Management (6); Environmental studies (6); Psychology applied (5); Philosophy (5); Medieval renaissance studies (5); Language linguistics (5); Art (5); Literature german dutch scandinavian (4); Literary theory criticism (4); Women s studies (3); History philosophy of science (3); Education educational research (3); Economics (3); Social issues (2); Folklore (2); Family studies (2); Behavioral sciences (2); Psychology educational (1); e Psychology (1). Destaca-se que os 
valores entre parênteses se referem à quantidade de artigos em cada categoria. Após o refinamento restaram 289 artigos, os quais fizeram parte das análises posteriores.

Ao analisar os resumos observou-se que nestas 289 publicações emergiram diferentes campos de estudos (memória, marca, história, cultura, por exemplo) demonstrando que a nostalgia vem despertando interesse em pesquisas que analisam a influência do passado no presente, conforme pode ser observado na Figura 1.

Figura 1 - Nuvem de palavras elaborada a partir dos resumos

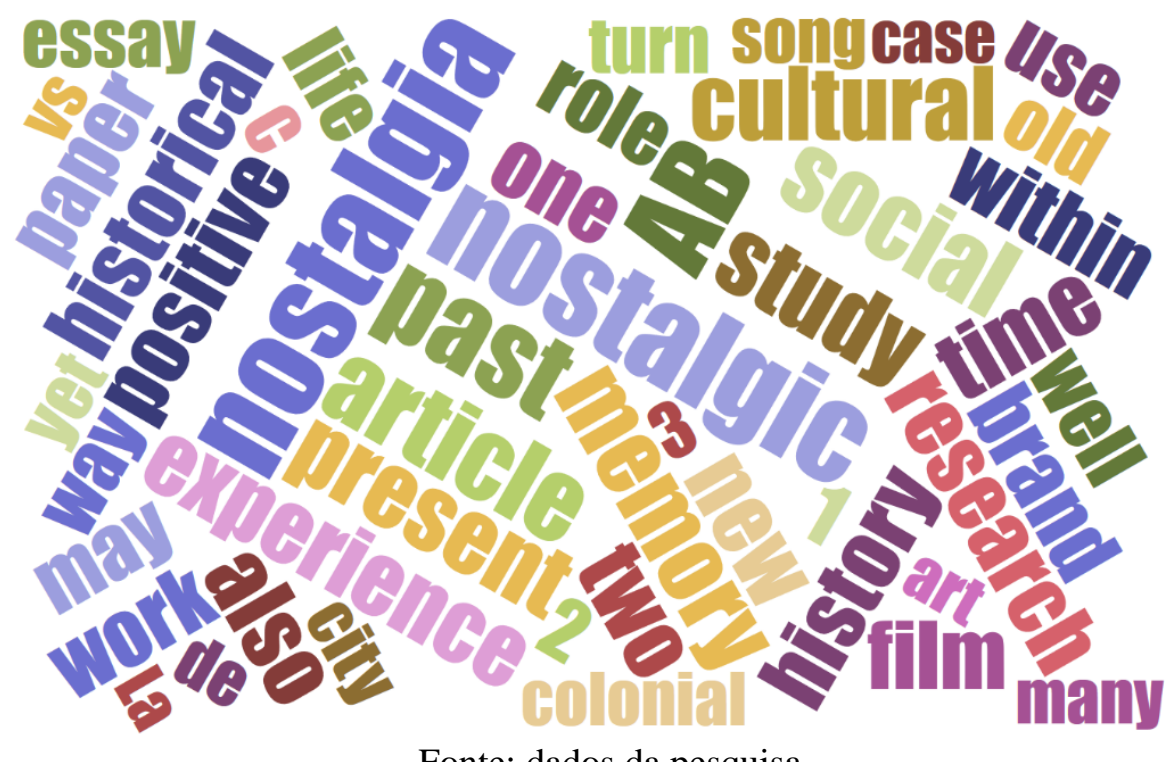

Fonte: dados da pesquisa.

Os estudos sobre o tema vêm crescendo ao longo do tempo, especialmente a partir do ano de 2009. A evolução das publicações nos últimos 20 anos é apresentada na Figura 2. 
Figura 2 - Evolução da produção científica nos últimos 20 anos

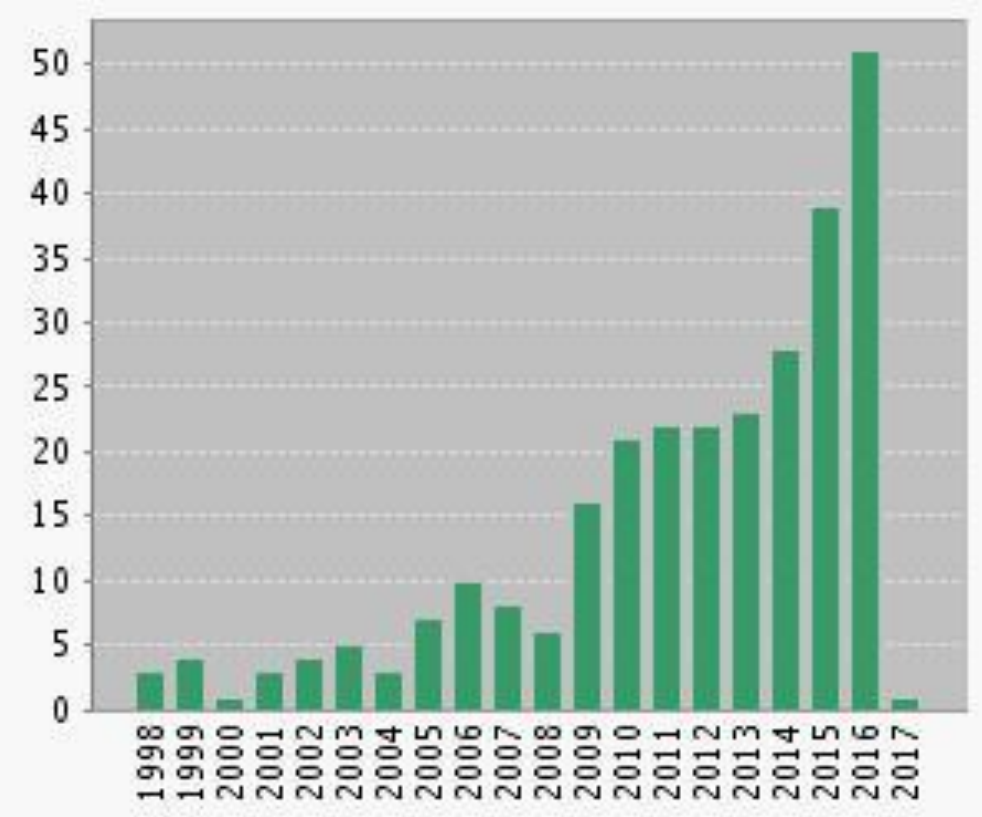

Fonte: Web Of Science

Ao todo, estas 289 publicações, apresentam 10.608 citações de outras publicações que incluem livros e artigos publicados em periódicos, as quais foram analisadas por meio da Análise de Cocitação - AC (co-citations analysis).

Small (1973) desenvolveu uma forma de analisar a ligação entre dois documentos, tendo por base o estudo da frequência com que estes são citados juntos, e denominou esta técnica como análise de cocitação. A premissa da AC é que, se dois ou mais documentos ou autores são citados juntos, em uma pesquisa posterior, na visão do autor citante, existe uma proximidade temática, conceitual ou metodológica entre os citados (SMIRAGLIA, 2011). A cocitação é definida por Small (1973) como a citação conjunta de dois artigos em uma literatura posterior. A mensuração da força da cocitação entre dois documentos, revela o grau de associação entre pares de documentos, de acordo com a compreensão da comunidade de autores citantes, ou seja, conforme são reconhecidos pelos citantes (SMALL, 1973). Desta forma, quem determina a proximidade e a interlocução de dois documentos não são os autores dos documentos, mas a comunidade científica que se apropria do conteúdo daqueles documentos e estabelece conexões enquanto está gerando novos conhecimentos (SMALL, 1973).

Buscando identificar a estrutura da produção científica que fornece base teórica para estudos sobre o uso da nostalgia no comportamento do consumidor analisou-se as cocitações das 
publicações sobre este tema, em que foi usada a seguinte regra: 103 publicações (81 artigos, 1 dissertação e 21 livros) mais citadas pelos autores das 289 publicações.

O Bibexcel, desenvolvido por Olle Person (Vanz e Stumpf, 2010), foi utilizado para realizar organizar os dados para a análise bibliométrica, em seguida utilizou-se o Statistical Package for the Social Sciences - SPSS para realizar a Análise Fatorial Exploratória (AFE). O Bibexcel foi alimentado com os dados das 289 publicações resultantes na busca realizada no WOS, após o refinamento das categorias. A partir do resultado gerado neste software as referências foram ordenadas por quantidade de citações em ordem decrescente, depois desta classificação, foi selecionada a amostra contendo as 103 publicações mais citadas, sendo que delas a com maior ocorrência foi de 84 citações e com menor 6 citações. Em seguida estas publicações foram usadas para geração da matriz de cocitação e, posteriormente análise fatorial exploratória no SPSS.

Das 103 publicações mais citadas, três são de metodologia (Hayes_2013, Preacher_Hayes_2004 e Baron_Kenny_1986) e foram excluídas para as análises posteriores, pois enquanto permaneciam nas análises no SPSS não gerava KMO geral, indicando que os dados não estavam adequados para a realização da AFE.

Ao inserir os dados das 100 publicações restantes, sem forçar a quantidade de fatores, os resultados apontaram para 11 fatores com variância total explicada de 82,52\% (superior ao valor mínimo de $60 \%$ recomendado por Hair et al. (2009), o KMO geral de 0,593 e, o teste de Esfericidade de Bartlett, que testa a significância geral de todas as correlações em uma matriz de correlação (Hair et al., 2009), cujo valor deve ser menor que 0,05 (Hair et al., 2009), foi de 0,000. Indicando a adequacidade dos dados para a realização da AFE.

Considerando que a AFE busca analisar o padrão de correlações existentes entre as variáveis e utilizar esses padrões de correlações para agrupar as variáveis em fatores (dimensões), tendo como propósito condensar e resumir os dados contidos em diversas variáveis originais em um número menor de novas dimensões (Hair et al., 2009), iniciaram-se as análises para ajustar o modelo onde observou-se que em 3 fatores todas as variáveis estavam com carga fatorial inferior 0,40 (mínimo aceitável segundo Hair et al., 2009). Assim, os dados foram analisados novamente fixando em 8 fatores onde se constatou que novamente em 1 fator não havia nenhuma variável com carga de 0,40 ou maior. Ao analisar com 7 fatores, em 2 deles todas as variáveis ficaram com valores inferiores a 0,40 . Em seguida, foi analisado com 5 fatores, sendo que em todos eles as cargas fatoriais ficaram superiores a 0,40, a variância total explicada foi de 74,20\%, o KMO geral de 0,556 e teste de esfericidade de Bartlett's de 0,000.

Ciências Sociais Aplicadas em Revista, v. 20, n. 38, p. 291-314, semestral, janeiro-junho, 2020. 
Seguiu-se nesta análise os procedimentos recomendados por Hair et al. (2009) avaliando o KMO de cada variável na matriz de anti-imagem (acima de 0,5), o KMO geral (acima de 0,5), a exclusão de variáveis com comunalidade abaixo de 0,5 , excluindo variáveis com cargas cruzadas (acima de 0,5 em mais de um fator) e, na matriz rotativa, analisou-se as cargas fatoriais, para que se alguma apresentasse carga negativa ela fosse excluída. As variáveis excluídas por apresentarem KMO individual inferior a 0,50 foram: Boym_2007 (KMO 0,238), Hobsbawm_Ranger_1983 (KMO 0,310), Anderson_1983 (KMO 0,321), Brown_Humphreys_2002 (KMO 0,435), Nora_1989 (KMO 0,441), Milligan_2003 (KMO 0,443), Strangleman_1999 (KMO 0,475), Turner_1987 (KMO 0,477) e Gabriel_1993 (KMO 0,499). Após a exclusão destas variáveis a variância total explicada ficou em 77,78\%, o KMO geral 0,726 e teste de Esfericidade de Bartlett manteve-se em 0,000 .

Na sequência buscou-se verificar as cumunalidades, a existência de variáveis com carga fatorial negativa e variáveis com carga cruzada. Observou-se que todas as variáveis apresentaram cumunalidades superiores a 0,50 e nenhuma variável apresentou carga fatorial negativa. No entanto, três variáveis apresentaram carga cruzada em mais de um fator, Tannock_1995 com cargas de 0,462 - fator 3 e 0,460 - fator 5; Leboe_Ansons_2006 com cargas de 0,450 - fator 1; 0,516 fator 2 e, 0,537 - fator 4; Nawas_Platt_1965 com cargas de 0,462 - fator 1; 0,501 - fator 4 e 0,431 - fator 5, em razão disso elas foram excluídas. Após a exclusão destas variáveis a variância total explicada ficou em 78,20\%, o KMO geral 0,727 e teste de Esfericidade de Bartlett manteve-se em 0,000. No modelo ajustado restaram 88 variáveis distribuídas nos 5 fatores.

\section{RESULTADOS}

Das 103 publicações (amostra selecionada antes da AFE) mais citadas nos 289 artigos resultantes da busca na base da WOS, a obra "Future Nostalgia" escrita por Boym (2001) foi a mais citada com 84 ocorrências, seguida obra de Davis (1979) "Yearning Yesterday" a qual foi citada em 83 artigos, conforme se apresenta na Tabela 1.

Tabela 1 - Publicações mais citadas nos 289 artigos

\begin{tabular}{l|l|l|l}
\hline Autores & Título & Quant. & $\%$ \\
\hline Boym_2001 & Future Nostalgia & 84 & $29,07 \%$ \\
\hline Davis_1979 & Yearning Yesterday & 83 & $28,72 \%$ \\
\hline Wildschut_Sedikides_Arndt_2006 & Nostalgia: Content, Triggers, Functions & 52 & $17,99 \%$ \\
\hline Batcho_1995 & Nostalgia: A Psychological Perspective & 38 & $13,15 \%$ \\
\hline
\end{tabular}

Ciências Sociais Aplicadas em Revista, v. 20, n. 38, p. 291-314, semestral, janeiro-junho, 2020. 


\begin{tabular}{|c|c|c|c|}
\hline Holbrook_1993 & $\begin{array}{l}\text { Nostalgia and Consumption Preferences: Some Emerging Patterns of } \\
\text { Consumer Tastes }\end{array}$ & 35 & $12,11 \%$ \\
\hline Zhou_Sedikides_Wildschut_Gao_2008 & Counteracting Loneliness on the Restorative Function of Nostalgia & 35 & $12,11 \%$ \\
\hline $\begin{array}{l}\text { Sedikides_Wildschut_Arndt_Routledge_ } \\
2008\end{array}$ & Nostalgia Past, Present, and Future & 31 & $10,73 \%$ \\
\hline $\begin{array}{l}\text { Hepper_Ritchie_Sedikides__ Wildschut } \\
\text { _2012 }\end{array}$ & $\begin{array}{l}\text { Odyssey's End: Lay Conceptions of Nostalgia Reflect its Original } \\
\text { Homeric Meaning }\end{array}$ & 30 & $10,38 \%$ \\
\hline Hofer_1934 & Medical dissertation on nostalgia & 30 & $10,38 \%$ \\
\hline Havlena_Holak_1991 & $\begin{array}{l}\text { The Good Old Days": Observations on Nostalgia and its Role In } \\
\text { Consumer Behavior }\end{array}$ & 29 & $10,03 \%$ \\
\hline $\begin{array}{l}\text { Routledge_Arndt_Sedikides_Wildschut_ } \\
2008\end{array}$ & A blast from the past: The terror management function of nostalgia & 29 & $10,03 \%$ \\
\hline $\begin{array}{l}\text { Wildschut_Sedikides_Routledge_Arndt_ } \\
\text { Cordaro_2010 }\end{array}$ & $\begin{array}{l}\text { Nostalgia as a Repository of Social Connectedness: The Role of } \\
\text { Attachment-Related Avoidance }\end{array}$ & 27 & $9,34 \%$ \\
\hline Holbrook_Schindler_1991 & Echoes of the dear departed past: Some work in progress on nostalgia & 24 & $8,30 \%$ \\
\hline Sedikides_Wildschut_Baden_2004 & Nostalgia: Conceptual issues and existential functions & 24 & $8,30 \%$ \\
\hline Stern_1992 & $\begin{array}{l}\text { Historical and Personal Nostalgia in Advertising Text: The Fin de } \\
\text { siècle Effect }\end{array}$ & 23 & $7,96 \%$ \\
\hline Holak_Havlena_1998 & $\begin{array}{l}\text { Feelings, Fantasies, and Memories: An Examination of the Emotional } \\
\text { Components of Nostalgia }\end{array}$ & 22 & $7,61 \%$ \\
\hline $\begin{array}{l}\text { Routledge_Arndt_Wildschut_Sedikides_ } \\
\text { Hart_Juhl_Vingerhoets_Schlotz_2011 }\end{array}$ & $\begin{array}{l}\text { The past makes the present meaningful: Nostalgia as an existential } \\
\text { resource }\end{array}$ & 22 & $7,61 \%$ \\
\hline $\begin{array}{l}\text { Barrett_Grimm_Robins_Wildschut_Sedi } \\
\text { kides_Janata_2010 }\end{array}$ & Music-evoked nostalgia: Affect, memory, and personality & 20 & $6,92 \%$ \\
\hline Baker_Kennedy_1994 & Death by nostalgia: A diagnosis of context-specific cases & 19 & $6,57 \%$ \\
\hline Lowenthal_1985 & The Past is a Foreign Country & 17 & $5,88 \%$ \\
\hline
\end{tabular}

Fonte: dados da pesquisa.

No SPSS, cada publicação foi tratada como uma variável. Com a AFE foi possível avaliar os padrões existentes entre as publicações citadas pelos 289 artigos. Nesta análise o primeiro teste executado foi o de Kayser-Meyer Olkin (KMO), que varia entre 0 e 1. O teste de KMO indica se a amostra pode ser tratada pelo método de análise fatorial (Williams; Onsman; Brown, 2010). Para ajustar o modelo, o valor do teste KMO de cada variável foi analisado. O valor mínimo indicado para do teste KMO para cada variável deveria ser 0,5. Assim, se o valor do KMO individual de uma variável era menor que 0,5 , a variável era excluída e análise fatorial executada novamente. Depois de ajustar o KMO individual, analisou-se a comunalidade de cada variável, sendo que todas ficaram superiores a 0,50 , se o valor da comunalidade é próximo de zero, isto indica que a variável tem baixa correlação com o fator (FÁVERO et al., 2009). O método de rotação ortogonal dos fatores foi o Varimax, um dos métodos mais utilizados, considerado por Hair et al. (2009) com sendo superior a outros métodos de rotação fatorial ortogonal para conseguir uma estrutura fatorial simplificada. Das 103 variáveis deste estudo, foram excluídas: 3 por serem de metodologia, 9 por 
apresentarem KMO individual inferior a 0,50 e, 3 por terem carga cruzada, restando 88 variáveis que compõe a trajetória conceitual e histórica dos estudos científicos sobre nostalgia. Cabe destacar, que somente uma variável era excluída por vez. Assim, a AFE foi executada diversas vezes para que as variáveis ficassem ajustadas.

O resultado final da AFE gerou um KMO geral de 0,727, a variância total explicada com 5 dimensões foi de 78,20\% e o teste de Esfericidade de Bartlett foi de 0,000, demonstrando que há correlação entre as variáveis. A análise de cocitação mede a relação entre dois artigos com base no número de publicações em que eles aparecem citados juntos em uma publicação posterior, tendo por objetivo identificar a base do conhecimento em um campo científico (SMALL, 1973). Desta forma, é possível afirmar que a estrutura da produção científica que fornece embasamento teórico para estudos sobre nostalgia é explicada em $78,20 \%$ por 88 autores.

Com a execução da análise fatorial exploratória, os artigos foram agrupados em fatores (dimensões). A partir deste agrupamento, os resumos de cada publicação foram analisados qualitativamente a fim de identificar os padrões apresentados pelas publicações e, em seguida, foram atribuídos nomes para cada dimensão.

Davis (1979) já ressaltava que a nostalgia tem efeitos positivos nas pessoas, pois ela protege a identidade pessoal contra ameaças de descontinuidade, sendo desenvolvida como uma resposta para adaptação e estabilização diante de um problema. Na presente pesquisa 36 artigos agruparamse na dimensão 1, a qual foi nominada “Efeitos positivos da nostalgia nas pessoas", corroborando com a visão de Davis (1979). Na Tabela 2 são apresentados os autores das publicações agrupadas na dimensão 1 .

Tabela 2 - Autores das publicações - Efeitos positivos da nostalgia nas pessoas

\begin{tabular}{l|c|l|c}
\multicolumn{1}{c|}{ Variáveis } & $\begin{array}{c}\text { Carga } \\
\text { fatorial }\end{array}$ & \multicolumn{1}{c|}{$\begin{array}{c}\text { Variáveis } \\
\text { fatorial }\end{array}$} \\
\hline Turner_Wildschut_Sedikides_2012 &, 952 & Sedikides_Wildschut_Baden_2004 &, 868 \\
\hline $\begin{array}{l}\text { Vess_Arndt_Routledge_Sedikides_Wildsc } \\
\text { hut_2012 }\end{array}$ &, 934 & $\begin{array}{l}\text { Wildschut_Sedikides_Routledge_Arndt_2 } \\
010\end{array}$ &, 865 \\
\hline $\begin{array}{l}\text { Stephan_Sedikides_Wildschut_2012 } \\
\text { Verplanken_2012 Ritchie_- }\end{array}$ &, 931 & $\begin{array}{l}\text { Sedikides_Wildschut_Arndt_Routledge_2 } \\
008\end{array}$ &, 849 \\
\hline $\begin{array}{l}\text { Hepper_ } \\
\text { Sedikides_Wildschut_2012 }\end{array}$ &, 919 & $\begin{array}{l}\text { Sedikides_Wildschut_Routledge_Arndt_H } \\
\text { epper_Zhou_2015 }\end{array}$ &, 849 \\
\hline $\begin{array}{l}\text { Juhl_Routledge_Arndt_Sedikides_Wildsc } \\
\text { hu_2010 }\end{array}$ &, 918 & Zhou_Sedikides_Wildschut_Gao_2008 &, 835 \\
\hline \begin{tabular}{l} 
VanTilburg_Igou_Sedikides_2013 \\
\hline
\end{tabular} &, 915 & $\begin{array}{l}\text { Zhou_Wildschut_Sedikides_Shi_Feng_20 } \\
\text { 12 }\end{array}$ &, 821 \\
\hline
\end{tabular}




\begin{tabular}{l|c|l|c}
\hline $\begin{array}{l}\text { Sedikides_Wildschut_Gaertner_Routledge } \\
\text { _Arndt_2008 }\end{array}$ &, 909 & Sedikides_Green_2006 &, 817 \\
\hline $\begin{array}{l}\text { Routledge_Arndt_Wildschut_Sedikides_H } \\
\text { art_Juhl_Vingerhoets_Schlotz_2011 }\end{array}$ &, 906 & $\begin{array}{l}\text { Routledge_Wildschut_Sedikides_Juhl_Arn } \\
\text { dt_2012 }\end{array}$ &, 766 \\
\hline Watson_Clark_Tellegen_1988 &, 905 & Zauberman_Ratner_Kim_2009 &, 763 \\
\hline $\begin{array}{l}\text { Hart_Sedikides_Wildschut_Arndt_Routle } \\
\text { dge_Vingerhoets_2011 }\end{array}$ &, 905 & CastelnuovoTedesco_1980 &, 760 \\
\hline $\begin{array}{l}\text { Routledge_Wildschut_Sedikides_Juhl_20 } \\
\text { 13 }\end{array}$ &, 898 & Mccann_1941 &, 731 \\
\hline Sedikides_Green_2009 &, 897 & Wildschut_Sedikides_Arndt_2006 &, 731 \\
\hline $\begin{array}{l}\text { Turner_Wildschut_Sedikides_Gheorghiu_ } \\
\text { 2013 }\end{array}$ &, 889 & Merchant_Ford_Rose_2011 &, 654 \\
\hline $\begin{array}{l}\text { Cheung_Wildschut_Sedikides_Hepper_Ar } \\
\text { ndt_Vingerhoets_2013 }\end{array}$ &, 883 & Hofer_1934 &, 619 \\
\hline Stephan_Walter_Wilutzky_2014 &, 879 & Kaplan_1987 &, 607 \\
\hline $\begin{array}{l}\text { Barrett_Grimm_Robins_Wildschut_Sediki } \\
\text { des_Janata_2010 }\end{array}$ &, 879 & Reynolds_2011 &, 570 \\
\hline $\begin{array}{l}\text { Routledge_Arndt_Sedikides_Wildschut_2 } \\
\text { 008 }\end{array}$ &, 878 & Mcadams_2001 &, 512 \\
\hline Fonte: & & \\
\hline
\end{tabular}

Fonte: dados da pesquisa.

Nesta dimensão a nostalgia é tratada como um recurso para melhorar o autoconceito e a conexão social; um estado emocional e cognitivo que remete às lembranças agridoce, ou seja, sentimentos agradáveis e desagradáveis; e, um artifício de autorregulação que gera afeto positivo, aumenta a autoestima, promove conexão social e alivia a ameaça existencial. Como um recurso existencial, a nostalgia serve de reforço para entendimento do sentido da vida, sendo importante para a saúde psicológica e bem-estar, além de aumentar o otimismo. A nostalgia é desencadeada por estados disfóricos, humor negativo e solidão, por exemplo, sendo que as narrativas nostálgicas refletem um efeito mais positivo do que negativo; pois é uma emoção auto relevante que envolve reviver o próprio passado. Nesta dimensão os autores tratam de emoções, memória e afeto, considerando a nostalgia como sendo um artifício psicológico que protege e promove a saúde mental.

A partir da constatação das dimensões positivas da nostalgia, alguns pesquisadores passaram a estudar se as estratégias usadas para conduzir as pessoas ao passado, poderiam ser úteis para persuadir os consumidores, ou seja, se teriam efeitos positivos em termos de lealdade à marca e intenção de consumir produtos que fizeram parte do seu passado ou do passado de outras pessoas. Estudos revelam que diversas marcas vêm usando esta estratégia para persuadir consumidores, seja por meio de apelos nostálgicos contidos nas propagandas (Muehling e Pascal, 2011; BambauerSachse e Gierl, 2009; Pascal, Sprott e Muehling, 2012) ou pela modificação visual das embalagens de marcas com longa permanência no mercado que estão regressando às origens (Stern, 1992; Brown, 2004) ou, ainda, por meio do lançamento de produtos com design antigo, mas com 
tecnologia atual (marca retrô), pois, as incertezas do presente levam as pessoas de olharem para o passado com saudade (Brown, Kozinets e Sherry, 2003) e diante da desorientação dos consumidores, o passado de uma marca oferece segurança (CATTANEO; GUERRINI, 2012).

$\mathrm{Na}$ análise fatorial exploratória 31 variáveis agruparam-se na dimensão 2, tratando do uso da nostalgia em propagandas. Esta dimensão foi nominada “Nostalgia no comportamento do consumidor”. Os autores das publicações e a carga fatorial são apresentados na Tabela 3.

Tabela 3 - Autores das publicações - Nostalgia no comportamento do consumidor

\begin{tabular}{l|c|l|c}
\multicolumn{1}{c|}{ Variáveis } & $\begin{array}{c}\text { Carga } \\
\text { fatorial }\end{array}$ & \multicolumn{1}{c}{ Variáveis } & $\begin{array}{c}\text { Carga } \\
\text { fatorial }\end{array}$ \\
\hline Muehling_Sprott_2004 &, 939 & Baumgartner_1992 &, 854 \\
\hline Unger_McConocha_Faier_1991 &, 938 & Havlena_Holak_1991 &, 851 \\
\hline Baker_Kennedy_1994 &, 935 & Loveland_Smeesters_Mandel_2010 &, 833 \\
\hline Sierra_McQuitty_2007 &, 932 & Hirsch_1992 &, 819 \\
\hline Pascal_Sprott_Muehling_2002 &, 931 & Holbrook_Schindler_1989 &, 810 \\
\hline Sujan_Bettman_Baumgartner_1993 &, 926 & Holbrook_Schindler_1991 &, 801 \\
\hline Brown_Kozinets_Sherry_2003 &, 926 & Holak_Havlena_1992 &, 794 \\
\hline Reisenwitz_Iyer_Cutler_2004 &, 923 & Holbrook_Schindler_1994 &, 789 \\
\hline Goulding_2002 &, 921 & Schindler_Holbrook_2003 &, 785 \\
\hline Belk_1990 &, 916 & Holbrook_Schindler_2003 &, 771 \\
\hline BraunLaTour_LaTour_Zinkhan_2007 &, 913 & Holak_Havlena_1998 &, 761 \\
\hline Holbrook_Schindler_1996 &, 884 & Batcho_1995 &, 750 \\
\hline Holak_Matveev_Havlena_2007 &, 870 & Belk_1988 &, 705 \\
\hline Merchant_LaTour_Ford_MichaelLaTour_2 &, 869 & Holbrook_1993 &, 675 \\
\hline 013 &, 857 & Davis_1979 &, 601 \\
\hline Goulding_2001 &, 855 & & \\
\hline Stern_1992 & & & \\
\hline
\end{tabular}

Fonte: dados da pesquisa.

As pesquisas agrupadas nesta dimensão tratam da influência positiva do uso de propagandas com apelos nostálgicos nas atitudes dos consumidores em relação ao anúncio e a marca, bem como as intenções de consumo; uso da nostalgia nos anúncios como forma de conduzir os consumidores às respostas comportamentais de consumo; atitudes e emoções como determinantes no comportamento de consumo, considerando que o uso de apelos nostálgicos em propagandas é capaz de afetar as preferências.

Estudos também foram realizados sobre retrobrand (produtos com desing antigo, mas com tecnologia atualizada) tratando do relançamento de marcas históricas como recurso para rejuvenescê-las e manter viva a essência da marca e sua história buscando, desta forma, além de conquistar a lealdade de consumidores que já tiveram experiências de consumo com determinada marca, também conquistar novos consumidores. Outras pesquisas centraram-se no estudo da 
propensão à nostalgia e construção e validação de escalas para mensurar os efeitos provocados pelas propagandas com apelos nostálgicos na intenção de consumo; o uso da música como recurso para desencadear um estado nostálgico nos consumidores; preditores da nostalgia (sexo, idade e atitudes em relação ao passado) para fornecer suporte aos anunciantes quando pretenderem usar a nostalgia como artefato para influenciar as decisões de compra.

Além disso, estudos focaram-se na classificação da nostalgia em pessoal e histórica, pois constataram que mesmo não tendo vivido e nem consumido alguns produtos que eram mais comuns no passado, há pessoas que sentem uma ligação com algumas marcas por terem ouvido relatos de outras pessoas e, em estudos anteriores já haviam constatado que a nostalgia vem sendo usada como um apelo que é altamente efetivo e persuasivo nas propagandas.

Na dimensão 3, nominada “Dimensões filosóficas e históricas da nostalgia” são abordados assuntos que remetem à cultura e progresso. A Tabela 4 apresenta os autores das publicações que se agruparam nesta dimensão.

$\underline{\text { Tabela } 4 \text { - Autores das publicações - Dimensões filosóficas e históricas da nostalgia }}$

\begin{tabular}{l|c|l|c}
\multicolumn{1}{c|}{ Variáveis } & $\begin{array}{c}\text { Carga } \\
\text { fatorial }\end{array}$ & \multicolumn{1}{c}{ Variáveis } & $\begin{array}{c}\text { Carga } \\
\text { fatorial }\end{array}$ \\
\hline Lowenthal_1989 &, 872 & Rosaldo_1989 &, 810 \\
\hline Jameson_1991 &, 850 & Halbwachs_1992 &, 787 \\
\hline Pickering_Keightley_2006 &, 846 & Wilson_2005 &, 783 \\
\hline Stewart_1988 &, 831 & Ritivoi_2002 &, 738 \\
\hline Stewart_1993 &, 828 & Chase_Shaw_1989 &, 713 \\
\hline Starobinski_Kemp_1966 &, 822 & Fritzsche_2001 &, 653 \\
\hline Lowenthal_1985 &, 817 & Boym_2001 &, 520 \\
\hline Casey_1987 &, 815 & & \\
\hline
\end{tabular}

Fonte: dados da pesquisa.

As pesquisas agrupadas nesta dimensão buscaram compreender as razões para a existência da nostalgia, fazendo referência ao pós-modernismo e ao capitalismo; as polêmicas culturais em torno da nostalgia e o progresso; modalidades de nostalgia; o papel do passado na formação das pessoas, permitindo dar sentido à vida. Abordaram ainda, interesses filosóficos em torno da nostalgia; a persistência das tradições e das memórias coletivas; dimensões filosóficas e históricas da nostalgia na vida dos imigrantes, em que buscaram mostrar uma ligação entre as tendências atuais na filosofia da identidade e os estudos interculturais.

Os estudos relacionados a este tema foram evoluindo ao longo dos anos e revelando que de fato a nostalgia é um sentimento agridoce, pois as pessoas podem recordar de acontecimentos que as deixam felizes ou tristes e, os estados de tristeza profunda podem ser entendidos como 
patológicos. As três publicações agrupadas na dimensão 4 são estudos mais antigos $(1977,1985$ e 1990) que, na presente pesquisa, foram nominados de “Nostalgia normal e patológica”. A dimensão 5, nominada “Nostalgia e significado das posses materiais" agrupou estudos sobre o significado das posses materiais da vida urbana contemporânea. Os autores das publicações das dimensões 4 e 5 são apresentados na Tabela 5.

Tabela 5 - Autores das publicações - Nostalgia normal e patológica e Nostalgia e significado das posses materiais

\begin{tabular}{|c|c|c|c|}
\hline Variáveis - Dimensão 4 & $\begin{array}{c}\text { Carga } \\
\text { fatorial }\end{array}$ & Variáveis - Dimensão 5 & $\begin{array}{c}\text { Carga } \\
\text { fatorial }\end{array}$ \\
\hline Werman_1977 & ,755 & Lowenthal_1985 &, 757 \\
\hline Hertz_1990 & ,635 & Glaser_Strauss_1967 & 677 \\
\hline Best_Edward_1985 & ,578 & Csikszentmihalyi_HochbergHalton_1981 & 670 \\
\hline
\end{tabular}

Fonte: dados da pesquisa.

As pesquisas agrupadas na dimensão 4 - “Nostalgia normal e patológica” tratam da nostalgia sob dois prismas: normal e patológico, destacando que ela se refere a uma experiência humana ubíqua que é evocada por estímulos particulares sob circunstâncias especiais e, embora geralmente ela ocorra de forma normal, também pode ocorrer de forma patológica. Memórias versus reminiscências versus anseios nostálgicos também são estudados nesta dimensão, analisando os mecanismos de enfrentamento de envelhecimento dos sobreviventes do Holocausto.

Na dimensão 5 - “Nostalgia e significado das posses materiais” é abordado o significado das coisas, que se refere ao estudo do significado das posses materiais da vida urbana contemporânea e das maneiras como as pessoas criam significados a partir de seu ambiente doméstico, ou seja, a partir do sentimento de ligação emocional que as pessoas têm sobre objetos domésticos comuns. Também é analisado o papel em constante mudança do passado na formação da vida das pessoas, considerando que o passado permite dar sentido ao presente, enquanto a imposição de restrições poderosas sobre a forma como o presente se desenvolve, pois cada geração remodela seu legado alinhando-o com as necessidades atuais.

Tendo em vista o objetivo desta pesquisa entende-se que é importante sumarizar a trajetória das definições de nostalgia ao longo do tempo. Esta pesquisa revelou que ao longo dos anos diversas definições de nostalgia foram surgindo e, a partir do estudo de Turner (1987), algumas delas foram sendo incorporadas à área de marketing com estudos sobre os efeitos no comportamento do consumidor. A Figura 3 apresenta a trajetória histórica das caracterizações/definições da palavra Nostalgia.

Ciências Sociais Aplicadas em Revista, v. 20, n. 38, p. 291-314, semestral, janeiro-junho, 2020. 
Figura 3 - Trajetória histórica das caracterizações/definições de nostalgia

\begin{tabular}{|c|c|c|}
\hline Autor (es) & Ano & Caracterização da nostalgia no decorrer dos anos \\
\hline Hofer & $1688 / 1934$ & $\begin{array}{l}\text { A palavra "nostalgia" tem uma derivação grega com duas raízes: "nostos" que } \\
\text { significa "voltar para casa ou para a terra natal" e "algos" referindo-se a "dor, } \\
\text { sofrimento ou dor". }\end{array}$ \\
\hline Turner & 1987 & $\begin{array}{l}\text { A nostalgia envolve quatro dimensões principais: (1) um sentido de declínio } \\
\text { e perda: espaço perdido e tempo perdido; (2) uma visão melancólica do } \\
\text { mundo contemporâneo baseada em uma crise percebida em nossa civilização } \\
\text { resultando em referências e valores perdidos; (3) um sentimento de perda da } \\
\text { liberdade individual e da autonomia; e (4) a ideia de uma perda de } \\
\text { simplicidade, autenticidade e espontaneidade emocional em uma cultura de } \\
\text { consumo em massa. }\end{array}$ \\
\hline Kaplan & 1987 & $\begin{array}{l}\text { "Sentimentos quentes sobre o passado, um passado que é imbuído de } \\
\text { lembranças felizes, prazeres e alegrias" e identificou-o como "um efeito } \\
\text { universal que resulta em um estado mental elevado, um estado de elevação, } \\
\text { inspiração relacionada a memórias particulares do passado. " (p. 465). }\end{array}$ \\
\hline Davis & 1979 & "Uma evocação positiva de um passado vivido" (p.18). \\
\hline Cavanaugh & 1989 & $\begin{array}{l}\text { "A nostalgia representa uma tentativa cognitiva de recuperar uma época em } \\
\text { que a vida era boa, sem perigo, segura e contente". Como evento cognitivo- } \\
\text { emocional, a nostalgia é "uma das maneiras de se desenvolver e manter a } \\
\text { identidade" e a reminiscência é "o principal meio pelo qual se mantém } \\
\text { relações com partes antigas do eu e pelas quais se mede a mudança pessoal } \\
\text { ao longo do tempo " (p. 603). }\end{array}$ \\
\hline Belk & 1990 & $\begin{array}{l}\text { "Um humor melancólico que pode ser provocado por um objeto, uma cena, } \\
\text { um cheiro ou uma tensão de música" (p.670). }\end{array}$ \\
\hline $\begin{array}{l}\text { Holbrook e } \\
\text { Schindler }\end{array}$ & 1991 & $\begin{array}{l}\text { "Preferência (apego geral, atitude positiva ou afeto favorável) em relação a } \\
\text { objetos (pessoas, lugares ou coisas) mais comuns (popular, na moda ou } \\
\text { amplamente difundida) quando era mais jovem (no início da idade adulta, na } \\
\text { adolescência, infância ou mesmo antes do nascimento " (p.330) }\end{array}$ \\
\hline Stern & 1992 & $\begin{array}{l}\text { "Um estado emocional em que um indivíduo anseia por uma versão } \\
\text { idealizada ou sanitizada de um período de tempo anterior" (p.11). }\end{array}$ \\
\hline Hirsch & 1992 & $\begin{array}{l}\text { Nostalgia não se relaciona a uma memória específica, mas a um estado } \\
\text { emocional. Este estado emocional idealizado é enquadrado dentro de uma era } \\
\text { passada e o anseio pelo estado emocional idealizado se manifesta como uma } \\
\text { tentativa de recriar aquela era passada reproduzindo as atividades realizadas } \\
\text { e, então, usando representações simbólicas do passado. }\end{array}$ \\
\hline Baker e Kennedy & 1994 & $\begin{array}{l}\text { "Um anseio sentimental ou agridoce por uma experiência, produto ou serviço } \\
\text { do passado" (p. 169). }\end{array}$ \\
\hline $\begin{array}{l}\text { Divard e Robert- } \\
\text { Demontrond }\end{array}$ & 1997 & $\begin{array}{l}\text { Uma reação emocional agridoce, possivelmente associada a uma atividade } \\
\text { cognitiva, e que é sentida por um indivíduo quando um estímulo externo ou } \\
\text { interno tem o efeito de transportá-lo em um período ou um evento } \\
\text { descendente do passado idealizado, registrado ou não na própria vida. }\end{array}$ \\
\hline Holak e Havlena & 1998 & $\begin{array}{l}\text { Um sentimento, uma emoção ou um humor complexo, de natureza positiva, } \\
\text { produzida por pensamentos relativos a coisas (objetos, pessoas, experiências } \\
\text { e ideias) associadas ao passado. }\end{array}$ \\
\hline $\begin{array}{l}\text { Summers, } \\
\text { Johnson e } \\
\text { McColi- } \\
\text { Kennedy } \\
\end{array}$ & 2001 & $\begin{array}{l}\text { "Sentimentos positivos e emoções controladas em relação a tudo o que vem } \\
\text { do passado (pessoas, lugares, objetos, experiências, etc.) e que ajuda a definir } \\
\text { o que somos atualmente" (p.19). }\end{array}$ \\
\hline $\begin{array}{l}\text { Holbrook e } \\
\text { Schindler } \\
\end{array}$ & 2003 & $\begin{array}{l}\text { A preferência (gosto geral, atitude positiva ou efeito favorável) com relação } \\
\text { a objetos (pessoas, lugares ou coisas) que eram mais comuns (populares, da }\end{array}$ \\
\hline
\end{tabular}




\begin{tabular}{|c|c|c|}
\hline & & $\begin{array}{l}\text { moda, ou mais presentes) quando se era mais jovem (na juventude, } \\
\text { adolescência, na infância, ou até mesmo antes do nascimento). }\end{array}$ \\
\hline $\begin{array}{l}\text { Sedikides, } \\
\text { Wildschut e } \\
\text { Baden }\end{array}$ & 2004 & $\begin{array}{l}\text { A nostalgia é uma experiência universal: diz respeito a todas as pessoas, } \\
\text { independentemente da idade, sexo, classe social, etnia ou outros } \\
\text { agrupamentos sociais. É uma emoção auto-relevante que envolve reviver o } \\
\text { próprio passado e, em particular, os eventos que envolvem os } \\
\text { relacionamentos importantes, mas passados. Apesar do seu conteúdo } \\
\text { agridoce, a nostalgia é predominantemente positiva. }\end{array}$ \\
\hline $\begin{array}{l}\text { Boerstler e } \\
\text { Madrigal }\end{array}$ & 2007 & $\begin{array}{l}\text { Estado emocional amargo-doce que contém várias emoções produzidas por } \\
\text { pensamentos relativos a coisas (objetos, pessoas, experiências, ideias) } \\
\text { associadas a um passado idealizado. }\end{array}$ \\
\hline $\begin{array}{l}\text { Zhou; } \\
\text { Wildschut; } \\
\text { Sedikides; Shi e } \\
\text { Feng }\end{array}$ & 2012 & $\begin{array}{l}\text { A nostalgia, um anseio sentimental por um passado pessoalmente experiente } \\
\text { e valorizado, é uma emoção social. Refere-se a outros significativos no } \\
\text { contexto de eventos de vida importantes e promove um senso de conexão } \\
\text { social. }\end{array}$ \\
\hline $\begin{array}{l}\text { Sedikides, } \\
\text { Wildschut, } \\
\text { Routledge, } \\
\text { Arndt, Hepper e } \\
\text { Zhou }\end{array}$ & 2015 & $\begin{array}{l}\text { A nostalgia é uma emoção auto-consciente, agridoce, mas } \\
\text { predominantemente positiva e fundamentalmente social. Ela surge de boas } \\
\text { lembranças misturadas com anseio sobre a infância, relacionamentos } \\
\text { próximos ou eventos atípicos positivos, e envolve uma trajetória de redenção. } \\
\text { É desencadeada por uma variedade de estímulos externos ou estados internos, } \\
\text { é prevalente, é universal, e é experimentado através das idades. }\end{array}$ \\
\hline
\end{tabular}

Fonte: elaborado pelos autores.

Estas caracterizações mostram que a palavra nostalgia foi usada inicialmente, por Hofer (1688/1934) para definir um estado patológico que envolvia sintomas fisiológicos e psicológicos, que remetiam ao sofrimento causado pela ânsia de voltar para casa e, foi usada para descrever o desânimo de mercenários suíços que lutavam em terras estrangeiras (Bassett, 2006), mas a tradução da dissertação de Hofer para a língua inglesa, no ano de 1934, estimulou novos estudos que revelaram as dimensões positivas da nostalgia e, em seguida, pesquisas constataram que os apelos nostálgicos, em anúncios ou em produtos, poderiam ser usados como artifícios para influenciar as intenções e atos de consumo e, diversos novos estudos foram surgindo buscando identificar preditores da nostalgia e efeitos dos apelos nostálgicos na atitude dos consumidores.

\section{CONSIDERAÇÕES FINAIS}

A nostalgia evoca recordações de situações agradáveis e desagradáveis do passado, por isso é considerada por alguns pesquisadores como uma qualidade agridoce. A análise de cocitação mede a relação entre dois artigos com base no número de publicações em que eles aparecem citados juntos, tendo por objetivo identificar a base do conhecimento em um campo científico. Assim, considerando a importância deste tema, a presente pesquisa buscou identificar a estrutura da produção científica que fornece a base teórica para estudos sobre a nostalgia no comportamento do consumidor. Realizou-se a análise de cocitações com o auxílio do software Bibexcel, para a 
organização dos dados e do software SPSS para a análise fatorial exploratória (AFE). Foram analisadas as cocitações que evidenciam a relação entre dois artigos com base no número de publicações em que eles aparecem citados juntos, tendo por objetivo identificar a base do conhecimento em um campo científico.

Das 289 publicações que fizeram parte desta pesquisa, mais antiga é a dissertação de Hofer, traduzida para a língua inglesa no ano de 1934, sendo este autor o prercursor dos estudos sobre a temática nostalgia, a qual naquela época foi tratada como uma doença. Por outro lado, Davis (1979) constatou que a nostalgia tinha aspectos positivos e que eles predominavam em relação aos negativos. O primeiro estudo a abordar o consumo foi o de Turner (1987), abrindo caminho para diversas novas pesquisas e abordagens de estudos que buscaram identificar e mensurar os efeitos da nostalgia, bem como do uso de apelos nostálgicos em propagandas e em produtos como influenciadores nas decisões de consumo.

Observou-se que nos últimos anos vem aumentando gradativamente a quantidade de produções científicas envolvendo o tema nostalgia e nestas publicações as duas obras mais citadas foram, respectivamente, Future Nostalgia (Boym, 2001 - 84 citações) e Yearning Yesterday (Davis, 1979 - 83 citações) e, os autores mais prolíficos entre as 289 publicações, foram, respectivamente, Sedikides, Wildschut, Routledge, Arndt, Havlena, Holak, Holbrook, Muehling e Merchant.

Ao longo dos anos as caracterizações e definições da palavra nostalgia também foram mudando e nelas foram sendo incorporadas novas perspectivas, por exemplo, nas primeiras pesquisas predominava a definição em termos de condições de trazer sensações de prazer e alegria para as pessoas, posteriormente as definições buscaram mostrar uma relação entre as recordações à objetos e coisas e, desde 1990 até o momento, há um fluxo de pesquisas buscando identificar os efeitos da nostalgia no comportamento de consumo.

$\mathrm{Na}$ análise de cocitação contida nos 289 artigos, a qual objetiva identificar a base do conhecimento em um campo científico relacionado a área em pauta, constatou-se que as publicações se agruparam em cinco dimensões, as quais receberam as seguintes nominações: Efeitos positivos da nostalgia nas pessoas; Nostalgia no comportamento do consumidor; Dimensões filosóficas e históricas da nostalgia; Nostalgia normal e patológica; e Nostalgia e significado das posses materiais.

A presente pesquisa apresenta algumas limitações entre elas, o recorte temporal e a opção pela base de dados WOS. Embora siga os procedimentos metodológicos proposto por Hair et al. 
(2009) para realizar AFE, a nominação dos fatores ocorreu com base na leitura crítica dos próprios autores não usando nenhum programa específico de análises qualitativas para nominá-los.

As contribuições propiciadas por este artigo apresentando a estrutura da produção científica que fornece base teórica para estudos sobre a nostalgia, por meio da análise de cocitações, é que nele se demonstra a relevância do tema e reforça a necessidade de continuidade destas investigações, visando a busca de um núcleo para entender o importante papel que as lembranças do passado exercem no comportamento dos indivíduos. Embora os aspectos econômicos, sociais, ambientais e o uso de novas tecnologias tenham significados ímpares no cotiano, há de se considerar que as recordações evocadas pela nostalgia também causam efeitos que se refletem nas ações e comportamentos das pessoas. Assim, este artigo abre perspectivas para novos estudos, em outras bases de artigos científicos que podem, de certa forma, ampliar o conhecimento da área.

\section{REFERÊNCIAS}

BAKER, Stacey Menzel; KENNEDY, Patricia F. Death By Nostalgia: A Diagnosis of ContextSpecific Cases. Advances in Consumer Research, v. 21, n. 1, p. 169-174, 1994.

BAMBAUER-SACHSE, Silke; GIERL, Heribert. Effects of Nostalgic Advertising through Emotions and the Intensity of the Evoked Mental Images. Advances in Consumer Research, v. 36, p. 391-398, 2009.

BARRETT, Frederick S. et al. Music-evoked nostalgia: affect, memory, and personality. Emotion, v. 10, n. 3, p. 390-403, 2010.

BASSETT, Jonathan F. An Experimental Test of the Discontinuity Hypothesis: Examining the Effects of Mortality Salience on Nostalgia. Journal of Articles in Support of the Null Hypothesis, v. 4, n. 1, p. 1-8, 2006.

BATCHO, Krystine Irene. Nostalgia: A psychological perspective. Perceptual and Motor Skills, v. 80, n. 1, p. 131-143, 1995.

BELK, Russell W. The role of possessions in constructing and maintaining a sense of past. ACR North American Advances, v. 17, n. 1, p. 669-676, 1990.

BELK, Russell W. Possessions and the sense of past. IN SV - Highways and Buyways: Naturalistic Research from the Consumer Behavior Odyssey, eds. Russell Belk, Provo, UT: Association for Consumer Research, p. 114-130, 1991.

BOERSTLER, Courtney; MADRIGAL, Robert. Nostalgia Advertisements: a Content Analysis. Advances in Consumer Research, v. 34, p. 424-426, 2007.

BORGMAN, Christine L.; FURNER, Jonathan. Scholarly communication and bibliometrics. Annual Review of Information Science and Technology, v. 36, n. 1, p. 2-72, 2002. 
BOYM, Svetlana. The future of nostalgia. Basic books, 2001.

BROWN, Stephen. O customer, where art thou?. Business Horizons, v. 47, n. 4, p. 61-70, 2004.

BROWN, Stephen; KOZINETS, Robert V.; SHERRY JR, John F. Teaching old brands new tricks: Retro branding and the revival of brand meaning. Journal of Marketing, v. 67, n. 3, p. 19-33, 2003.

Castelnuovo-Tedesco, P. (1980). Reminiscence and nostalgia: The pleasure and pain of remembering. The course of life: Psychoanalytic Contributions Toward Understanding Personality Development, 3, 104-118.

CASTELNUOVO-TEDESCO, Pietro. Reminiscence and nostalgia: The pleasure and pain of remembering. The Course of Life: Psychoanalytic Contributions Toward Understanding Personality Pevelopment, v. 3, p. 104-118, 1980.

CATTANEO, Eleonora; GUERINI, Carolina. Assessing the revival potential of brands from the past: How relevant is nostalgia in retro branding strategies?. Journal of Brand Management, v. 19, n. 8, p. 680-687, 2012.

CAVANAUGH, John C. I have this feeling about everyday memory aging. Educational Gerontology: An International Quarterly, v. 15, n. 6, p. 597-605, 1989.

CHEUNG, Wing-Yee et al. Back to the future: Nostalgia increases optimism. Personality and Social Psychology Bulletin, v. 39, n. 11, p. 1484-1496, 2013.

Davis, Fred. Yearning for yesterday: A sociology of nostalgia. Free Press, 1979.

DIVARD, Ronan; ROBERT-DEMONTROND, Philippe. Nostalgia: um tema recente nas pesquisas de marketing. Research and Applications in Marketing (French Edition), v. 12, n. 4, pág. 41-62, 1997.

FÁVERO, Luiz Paulo et al. Análise de dados: modelagem multivariada para tomada de decisões. Elselvier, 2009.

HAIR, Joseph F. et al. Análise multivariada de dados. Bookman editora, 2009.

HART, Claire M. et al. Nostalgic recollections of high and low narcissists. Journal of Research in Personality, v. 45, n. 2, p. 238-242, 2011.

HAVLENA, William J.; HOLAK, Susan L. " The Good Old Days": Observations On Nostalgia and Its Role In Consumer Behavior. Advances in Consumer Research, v. 18, n. 1, 1991.

HEPPER, Erica G. et al. Odyssey's end: lay conceptions of nostalgia reflect its original Homeric meaning. Emotion, v. 12, n. 1, p. 102, 2012.

HIRSCH, Alan R. Nostalgia: a Neuropsychiatric Understanding. ACR North American Advances IN Consumer Research, v. 19, n. 1, p.390-395, 1992. 
Hofer, Johannes. Medical Dissertation on Nostalgia. ANSPACH, Carolyn Kiser (trans.). Medical dissertation on nostalgia by Johannes Hofer, 1688. Bulletin of the Institute of the History of Medicine, v. 2, n. 6, p. 376-391, 1934.

HOLAK, Susan L.; HAVLENA, William J. Feelings, fantasies, and memories: An examination of the emotional components of nostalgia. Journal of Business Research, v. 42, n. 3, p. 217-226, 1998.

HOLAK, Susan L.; HAVLENA, William J. Nostalgia: An Exploratory Study of Themes and Emotions in the Nostalgic Experience. Advances in Consumer Research, v. 19, n. 1, 1992.

HOLBROOK, Morris B. Nostalgia and consumption preferences: Some emerging patterns of consumer tastes. Journal of Consumer Research, v. 20, n. 2, p. 245-256, 1993.

HOLBROOK, Morris B.; SCHINDLER, Robert M. Market segmentation based on age and attitude toward the past: Concepts, methods, and findings concerning nostalgic influences on customer tastes. Journal of Business Research, v. 37, n. 1, p. 27-39, 1996.

HOLBROOK, Morris B.; SCHINDLER, Robert M. Nostalgic bonding: Exploring the role of nostalgia in the consumption experience. Journal of Consumer Behaviour: An International Research Review, v. 3, n. 2, p. 107-127, 2003.

HOLBROOK, Morris B.; SCHINDLER, Robert M. Echoes of the Dear Departed Past: Some Work in Progress on Nostalgia. Advances in Consumer Research, v. 18, n. 1, 1991.

IYER, Aarti; JETTEN, Jolanda. What's left behind: Identity continuity moderates the effect of nostalgia on well-being and life choices. Journal of Personality and Social Psychology, v. 101, n. 1, p. 94, 2011.

JUHL, Jacob et al. Fighting the future with the past: Nostalgia buffers existential threat. Journal of Research in Personality, v. 44, n. 3, p. 309-314, 2010.

KAPLAN, Harvey, A. The psychopathology of nostalgia. Psychoanalytic Review, v. 74, n. 4, p. 465-486, 1987.

KESSOUS, Aurélie. Nostalgia and brands: a sweet rather than a bitter cultural evocation of the past. Journal of Marketing Management, v. 31 (17-18), p. 1899-1923, 2015.

KESSOUS, Aurélie; ROUX, Elyette; CHANDON, Jean-Louis. Consumer-brand relationships: A contrast of nostalgic and non-nostalgic brands. Psychology \& Marketing, v. 32, n. 2, p. 187-202, 2015 .

LOWENTHAL, David. The past is a foreign country-revisited. Cambridge University Press, 2015.

MCADAMS, Dan P. The psychology of life stories. Review of General Psychology, v. 5, n. 2, p. 100-122, 2001. 
MCCANN, Willis H. Nostalgia: a review of the literature. Psychological Bulletin, v. 38, n. 3, p. $165,1941$.

MCCANN, Willis H. Nostalgia: A descriptive and comparative study. The Pedagogical Seminary and Journal of Genetic Psychology, v. 62, n. 1, p. 97-104, 1943.

MERCHANT, Altaf; FORD, John B.; ROSE, Gregory. How personal nostalgia influences giving to charity. Journal of Business Research, v. 64, n. 6, p. 610-616, 2011.

MERCHANT, Altaf et al. How strong is the pull of the past?: Measuring personal nostalgia evoked by advertising. Journal of Advertising Research, v. 53, n. 2, p. 150-165, 2013.

MUEHLING, Darrel D.; PASCAL, Vincent J. An empirical investigation of the differential effects of personal, historical, and non-nostalgic advertising on consumer responses. Journal of Advertising, v. 40, n. 2, p. 107-122, 2011.

MUEHLING, Darrel D.; PASCAL, Vincent J. An involvement explanation for nostalgia advertising effects. Journal of Promotion Management, v. 18, n. 1, p. 100-118, 2012.

MUEHLING, Darrel D.; SPROTT, David E.; SULTAN, Abdullah J. Exploring the boundaries of nostalgic advertising effects: A consideration of childhood brand exposure and attachment on consumers' responses to nostalgia-themed advertisements. Journal of Advertising, v. 43, n. 1, p. 73-84, 2014.

MUEHLING, Darrel D.; SPROTT, David E.; SPROTT, David E. The power of reflection: An empirical examination of nostalgia advertising effects. Journal of Advertising, v. 33, n. 3, p. 25$35,2004$.

ORTH, Ulrich R.; GAL, Steffi. Persuasive mechanisms of nostalgic brand packages. Applied Cognitive Psychology, v. 28, n. 2, p. 161-173, 2014.

PASCAL, Vincent J.; SPROTT, David E.; MUEHLING, Darrel D. The influence of evoked nostalgia on consumers' responses to advertising: An exploratory study. Journal of Current Issues \& Research in Advertising, v. 24, n. 1, p. 39-47, 2002.

REYNOLDS, Simon. Retromania: Pop Culture's Addiction to Its Own Past. Farrar, Straus and Giroux, 2011.

ROUTLEDGE, Clay et al. A blast from the past: The terror management function of nostalgia. Journal of Experimental Social Psychology, v. 44, n. 1, p. 132-140, 2008.

ROUTLEDGE, Clay et al. The past makes the present meaningful: nostalgia as an existential resource. Journal of personality and social psychology, v. 101, n. 3, p. 638, 2011.

ROUTLEDGE, Clay et al. Nostalgia as a resource for psychological health and well-being. Social and Personality Psychology Compass, v. 7, n. 11, p. 808-818, 2013.

ROUTLEDGE, Clay et al. The power of the past: Nostalgia as a meaning-making resource. Memory, v. 20, n. 5, p. 452-460, 2012. 
SCHINDLER, Robert M.; HOLBROOK, Morris B. Nostalgia for early experience as a determinant of consumer preferences. Psychology \& Marketing, v. 20, n. 4, p. 275-302, 2003.

SEDIKIDES, Constantine; GREEN, Jeffrey D. Memory as a self-protective mechanism. Social and Personality Psychology Compass, v. 3, n. 6, p. 1055-1068, 2009.

SEDIKIDES, Constantine; WILDSCHUT, Tim; BADEN, Denise. Nostalgia Conceptual Issues and Existential Functions. IN, Greenberg, Jeff, Koole, Sander L. and Pyszczynski, Tom (eds.). Handbook of Experimental Existential Psychology. New York, USA. Guildford Press, pp. 200214, 2004.

SEDIKIDES, Constantine et al. Nostalgia: Past, present, and future. Current directions in psychological science, v. 17, n. 5, p. 304-307, 2008.

SEDIKIDES, Constantine et al. Nostalgia as enabler of self-continuity. IN F. Sani (Ed.). Individual and Collective Self-continuity: Psychological Perspectives. Mahwah, NJ: Lawrence Erlbaum Associates, 2008.

SEDIKIDES, Constantine et al. To Nostalgize: Mixing Memory with Affect and Desire. Psychology, v. 51, n. 1, p. 189-273, 2015.

SMALL, Henry. Co-citation in the scientific literature: A new measure of the relationship between two documents. Journal of the American Society for information Science, v. 24, n. 4, p. 265269, 1973.

SMIRAGLIA, Richard P. ISKO 11's diverse bookshelf: an editorial. KO KNOWLEDGE ORGANIZATION, v. 38, n. 3, p. 179-186, 2011.

STAROBINSKI, Jean; KEMP, William S. The idea of nostalgia. Diogenes, v. 14, n. 54, p. 81-103, 1966.

STEPHAN, Achim; WALTER, Sven; WILUTZKY, Wendy. Emotions beyond brain and body. Philosophical Psychology, v. 27, n. 1, p. 65-81, 2014.

STEPHAN, Elena; SEDIKIDES, Constantine; WILDSCHUT, Tim. Mental travel into the past: Differentiating recollections of nostalgic, ordinary, and positive events. European Journal of Social Psychology, v. 42, n. 3, p. 290-298, 2012.

STERN, Barbara B. Historical and personal nostalgia in advertising text: The fin de siecle effect. Journal of Advertising, v. 21, n. 4, p. 11-22, 1992.

SUMMERS, Jane; MCCOLL-KENNEDY, Janet; JOHNSON MORGAN, Melissa. Evoking the past: exploring nostalgia's relevance to sport consumption. Asia Pacific Advances in Consumer Research, v. 4, p. 108-113, 2001.

TURNER, Bryan S. A note on nostalgia. Theory, Culture \& Society, v. 4, n. 1, p. 147-156, 1987. 
TURNER, Rhiannon N.; WILDSCHUT, Tim; SEDIKIDES, Constantine. Dropping the weight stigma: Nostalgia improves attitudes toward persons who are overweight. Journal of Experimental Social Psychology, v. 48, n. 1, p. 130-137, 2012.

TURNER, Rhiannon N. et al. Combating the mental health stigma with nostalgia. European Journal of Social Psychology, v. 43, n. 5, p. 413-422, 2013.

VAN TILBURG, Wijnand AP; IGOU, Eric R.; SEDIKIDES, Constantine. In search of meaningfulness: Nostalgia as an antidote to boredom. Emotion, v. 13, n. 3, p. 450, 2013.

VANZ, Samile Andrea de Souza; STUMPF, Ida Regina Chitto. Procedimentos e ferramentas aplicados aos estudos bibliométricos. Informação \& Sociedade: estudos, v. 20, n. 2, p. 67-75, 2010.

VERPLANKEN, Bas. When bittersweet turns sour: Adverse effects of nostalgia on habitual worriers. European Journal of Social Psychology, v. 42, n. 3, p. 285-289, 2012.

VESS, Matthew et al. Nostalgia as a resource for the self. Self and Identity, v. 11, n. 3, p. 273284, 2012.

WATSON, David; CLARK, Lee Anna; TELLEGEN, Auke. Development and validation of brief measures of positive and negative affect: the PANAS scales. Journal of personality and social psychology, v. 54, n. 6, p. 1063, 1988.

WILDSCHUT, Tim et al. Nostalgia: content, triggers, functions. Journal of Personality and Social Psychology, v. 91, n. 5, p. 975, 2006.

WILDSCHUT, Tim et al. Nostalgia as a repository of social connectedness: the role of attachmentrelated avoidance. Journal of Personality and Social Psychology, v. 98, n. 4, p. 573-586, 2010.

WILDSCHUT, Tim et al. Nostalgia: content, triggers, functions. Journal of Personality and Social Psychology, v. 91, n. 5, p. 975-993, 2006.

WILLIAMS, Brett; ONSMAN, Andrys; BROWN, Ted. Exploratory factor analysis: A five-step guide for novices. Australasian Journal of Paramedicine, v. 8, n. 3, p. 1-13, 2010.

ZAUBERMAN, Gal; RATNER, Rebecca K.; KIM, B. Kyu. Memories as assets: Strategic memory protection in choice over time. Journal of Consumer Research, v. 35, n. 5, p. 715-728, 2009.

ZHOU, Xinyue et al. Counteracting loneliness: On the restorative function of nostalgia. Psychological science, v. 19, n. 10, p. 1023-1029, 2008.

ZHOU, Xinyue et al. Nostalgia: The gift that keeps on giving. Journal of Consumer Research, v. 39, n. 1, p. 39-50, 2012. 